\title{
Is Association between Mortality and Air Pollution due to a Short Temporal Displacement?
}

\author{
Diana Šimić ${ }^{1}$, Mladen Pavlović ${ }^{1}$, Krešimir Šega ${ }^{1}$, Janko Hršak ${ }^{1}$, \\ Vladimira Vađić ${ }^{1}$ and Višnja Šojat ${ }^{2}$ \\ ${ }^{1}$ Institute for Medical Research and Occupational Health, Zagreb, Croatia \\ 2 Meteorological and Hydrological Service of Croatia, Zagreb, Croatia
}

\begin{abstract}
Standard methodology for analysis of air pollution epidemiological time series expresses effects in terms of relative risk, i.e. increases in the number of events associated with a short term increase in air pollution. However, even large relative mortality rates may in fact reflect a very small effect in terms of person-years life loss. In Zagreb, mortality in 1995-1997 was significantly associated with concentrations of nitrogen dioxide $\left(\mathrm{NO}_{2}\right)$. We have used STL decomposition of time series into additive components of decreasing smoothness to test the hypothesis that mortality - air pollution association is due to short term mortality displacement. According to our results association between mortality and concentrations of $\mathrm{NO}_{2}$ remains statistically significant at time scales ranging from a few days to 1-2 months.
\end{abstract}

Keywords: mortality, air pollution, harvesting, mortality displacement, LOESS, STL

Introduction

Interest in air pollution and its health effects has been growing steadily during the last decade. Many publications associate adverse health effects with air pollution levels previously considered safe. Several large national and international studies of air pollution health effects are based on epidemiological time series (e.g. Samet et. al. 2000; Katsouyanni et al. 1996, 1997). Even though results from various places are convincingly consistent, the time series approach has been criticised for uncertainties in model selection and exposure measurement, and for not being able to provide effect size estimates in terms of the usual person-years life loss (e.g. Lipfert and Wyzga, 1995, 1997). Even with large relative mortality rates associated with increased air pollution levels, actual effects might be rather small if all deaths came from a pool of frail individuals who would have otherwise died just a few days later. This hypothesis is known as "harvesting" or "mortality displacement". Preliminary results show that all short term effects cannot be attributed to mortality displacement (Zeger et al. 1999, Schwartz 2000). Significant associations between mortality and air pollution were previously found in Zagreb, Croatia (Šimić et al. 1998, 1999). In this paper we aim to test whether this effect can be attributed to harvesting.

\section{Material and Methods}

The analyses are based on epidemiological time series of daily data from the city of Zagreb, capital of Croatia for the three year period from 1995 to 1997 . Mortality data were supplied by the Croatian Bureau of Statistics, from the official mortality database. They consisted of all deaths in the city of Zagreb, excluding deaths due to external causes (ICD10 codes V01-Y89). Meteorological data included daily minimum, average and maximum temperature, air pressure and relative humidity measured at one station by the Meteorological and Hydrological Service of Croatia. Concentrations of air pollutants were measured by the staff of the Environmental Hygiene Unit of the Institute for Medical 
Research and Occupational Health. They comprised average daily concentrations of nitrogen dioxide (measured at six stations), sulphur dioxide (measured at four stations) and black smoke (measured at four stations). Additional air pollution data were provided by the Meteorological and Hydrological Service of Croatia for concentrations of nitrogen dioxide (measured at two stations). Details are given elsewhere (Šimić et al. 1999).

Association between mortality and air pollution was analysed using a Poisson generalised additive model (GAM) accounting for overdispersion (Hastie and Tibshirani, 1990). Choice of the number of degrees of freedom and lags was based on the corrected Akaike information criterion $\mathrm{AIC}_{C}$ (Simonoff and Tsai, 1999). The harvesting hypothesis was tested using the method proposed by Schwartz (2000). All time series were decomposed into longscale (time trend and seasonal fluctuations), midscale and shortscale components using the STL procedure (Cleveland et al. 1990). STL procedure decomposes a time series into a sum of components of increasingly lower smoothness using a local regression LOESS. Smoothness of each component can be flexibly adjusted through the width of the window used by the local regression. For the longscale and seasonal components, the window was set at 120 days. We analysed four decompositions with the midscale component window width set at 15, 30, 45 and 60 days. If the effect of air pollution was due to harvesting, then there would be no association between midscale components of air pollution and mortality time series accounting for weather. For each smoothing window width a separate loglinear additive model was fitted. Outcome and predictors used in the original model (Šimić et al. 1999) were replaced with respective midscale components. The three year mean was added back to the midscale components to retain the scaling of the original model.

\section{Results}

Figure 1 presents the STL decomposition of total mortality with a midscale component smoothing window width of 30 days. Decompositions with varying midscale component smoothing window widths differed in the central and the bottom panels only. With a longer smoothing window, there was more smoothing in the central panel (midscale component) and less smoothing in the bottom panel (residual i.e. shortscale component). The fourth panel from the top showing the seasonal component of total mortality illustrates the flexibility of shape provided by the LOESS smoothing.

General mortality - 30 days window

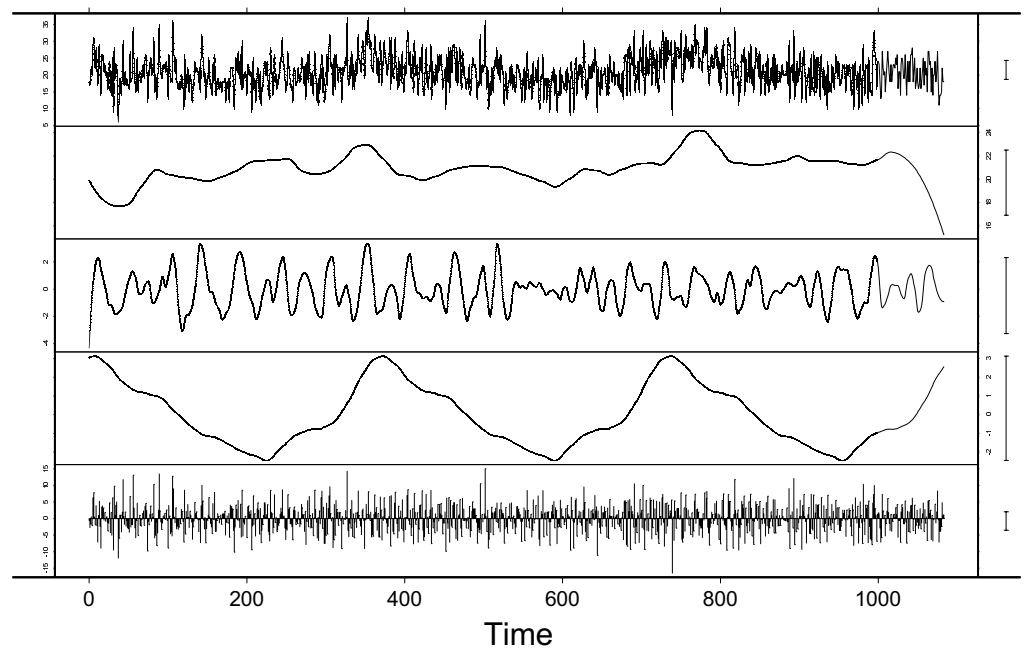

Fig. 1. STL decomposition of daily general mortality. Top to bottom panels represent: observed daily mortality, longscale trend with smoothing window width of 120 days, midscale component with smoothing window width of 30 days, seasonal component with smoothing window width of 120 days, shortscale residual. 


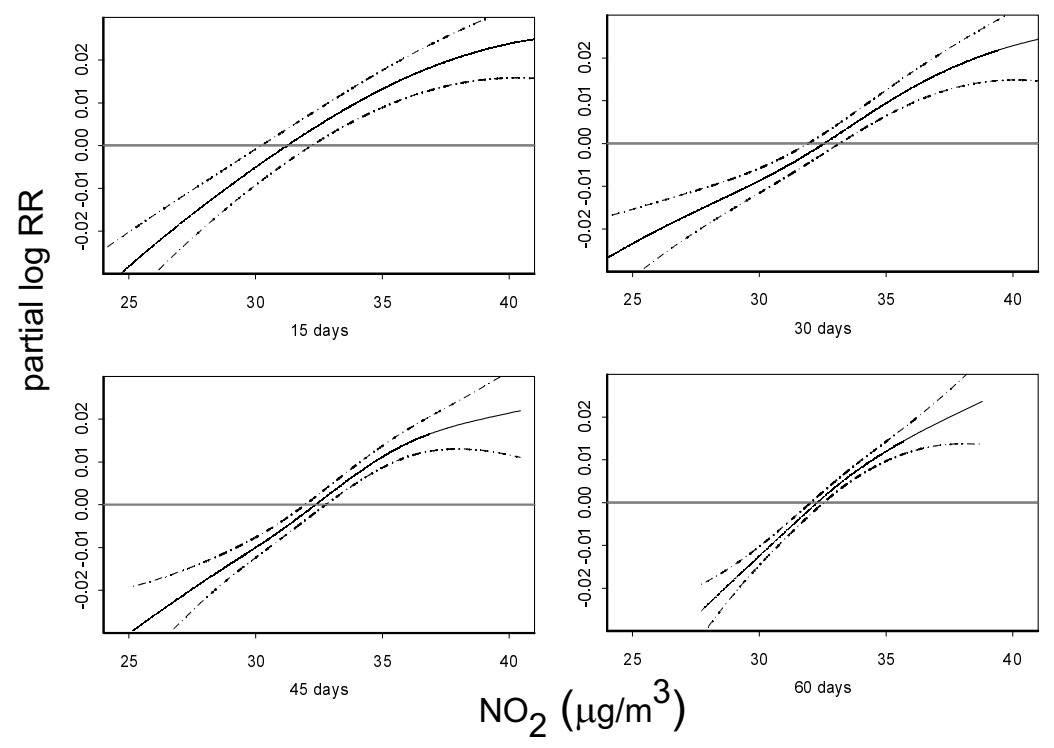

Fig. 2. Partial additive terms for association between midscale components of general mortality and $\mathrm{NO}_{2}$ for smoothing window widths of $15,30,45$ and 60 days.

Figure 2 presents partial additive terms for $\mathrm{NO}_{2}$ from GAM models with midscale components of varying smoothing window widths. With increased smoothing of midscale components their range decreases. We have, however, retained the same axis scaling in all panels to enable comparison of slopes. The range of the $x$-axes was from 24 to $41 \mu \mathrm{g} / \mathrm{m}^{3}$. It included $84.6 \%$ of $\mathrm{NO}_{2}$ midscale data for the 15-day smoothing window width, $95.8 \%$ of data for the 30-day smoothing window width, and the whole range for 45 and 60-day smoothing window widths. The additive term for $\mathrm{NO}_{2}$ was modelled as a spline function with two degrees of freedom. Visually, there was no difference between the slopes of the partial additive terms obtained from GAM fits for different smoothing window widths.

The common range of all four $\mathrm{NO}_{2}$ midscale components covered values from 27.7 to 38.8 $\mu \mathrm{g} / \mathrm{m}^{3}$. Table 1 summarises relative risks for the increase of $\mathrm{NO}_{2}$ from 30 to $35 \mu \mathrm{g} / \mathrm{m}^{3}$ for the original model, and models for midscale STL components with increasing smoothing window widths. If association between daily mortality and concentrations of $\mathrm{NO}_{2}$ were due only to short temporal displacement, we would observe a decrease in the relative risks with more smoothing (larger smoothing window). The results in Table 1 do not show a decrease in the effect size.

\begin{tabular}{cccc}
\hline \hline \multirow{2}{*}{$\begin{array}{c}\text { Smoothing window } \\
\text { width }\end{array}$} & RR & \multicolumn{2}{c}{ 95\% confidence limits } \\
\cline { 3 - 4 } & & Lower & Upper \\
\hline 0 & 1.0128 & 0.9988 & 1.0270 \\
15 & 1.0184 & 1.0123 & 1.0246 \\
30 & 1.0183 & 1.0141 & 1.0226 \\
45 & 1.0214 & 1.0179 & 1.0250 \\
60 & 1.0248 & 1.0215 & 1.0280 \\
\hline
\end{tabular}

Table 1. Relative mortality risk (RR) associated with an increase in the concentration of $\mathrm{NO}_{2}$ from 30 to $35 \mu \mathrm{g} / \mathrm{m}^{3}$ and $95 \%$ confidence limits for various midscale component smoothing window widths in the STL algorithm. 


\section{Discussion}

The method we used was introduced by Schwartz (2000) for the assessment of harvesting in the association between concentrations of $\mathrm{PM}_{2.5}$ and all-cause mortality, mortality due to ischemic hearth disease (IHD), chronic obstructive pulmonary disease (COPD) and pneumonia in Boston, Massachusetts. He has found some evidence of harvesting for COPD deaths and deaths due to pneumonia. His results suggested that COPD deaths were brought forward by a few months. For pneumonia, however, there were a few deaths brought forward by a few days, but on the scale of 1 to 2 months the effect was even larger than in the original time series. For IHD and all-cause mortality long term effects were definitely larger. Zeger et al. (1999) used different methodology to obtain harvesting-resistant estimates of the total suspended particles relative risk. Their estimates were also actually larger than those obtained on original data. Our results for association between all-cause mortality and $\mathrm{NO}_{2}$ are similar. The effect size appears to slightly increase with a longer time scale, suggesting that deaths are brought forward by nontrivial amounts of time. Due to the presence of seasonal effects, this methodology cannot be extended for longer time scales. Interpretation of regression parameters is not as clear as that for the original time series. However, the fact that association between mortality and air pollution cannot be entirely attributed to short temporal displacement warrants further research into models of harvesting that enable easier interpretation in the usual epidemiological terms.

\section{Acknowledgments}

This research was supported by the Ministry for Science and Technology of the Republic of Croatia through projects 00220307, 00220201 and 00220202 .

\section{References}

[1] Cleveland, R.B., Cleveland, W.S., McRae, J.E., TERPENNING, I., (1990), "STL: A seasonal trend decomposition procedure based on LOESS", J. Offic. Statist., Vol. 6, pp. 3-73.
[2] Hastie, T.J. AND TIBShiRAni, R.J., (1990), Generalized Additive Models, Chapman \& Hall, New York, NY.

[3] KatsouyanNI, K., SchWARTZ, J., SPIX, C., TOUlOUMI, G., ZMIROU, D., ZANOBETTI, A., WoJTYNIAK, B., VONK, J.M., TOBIAS, A., PONKA, A., Medina, S., BACharova, L., ANDERSON, H.R., (1996), "Short term effects of air pollution on health: A European approach using epidemiologic time series data: the APHEA protocol", J. Epidemiol. Comm. Health, Vol. 50, Suppl. 1, pp. S12-S18.

[4] Katsouyanni, K., Touloumi, G., SpiX, C., Schwartz, J., BALDUCCI, F., MEDINA, S., ROSSI, G., WojTyniak, B., SunYer, J., BACHAROVA, L., SCHOUTEN, J.P., PONKA, A., ANDERSON, H.R., (1997), "Short term effects of ambient sulphur dioxide and particulate matter on mortality in 12 European cities: results from time series data from the APHEA project", BMJ, Vol. 314, pp. 16581663.

[5] LIPFERT, F.W. AND WYZGA, R.E., (1995), "Air pollution and mortality: Issues and uncertainties", $J$. Air Waste Manage. Assoc., Vol. 45, pp. 949-966.

[6] LIPFERT, F.W. AND WyZGA, R.E., (1997), “Air pollution and mortality: The implications of uncertainties in regression modeling and exposure measurement", J. Air Waste Manage. Assoc., Vol. 47, pp. $517-523$.

[7] SAMET, J.M., DOMINICI, F., ZEGER, S.L., SCHWARTZ, J., DOCKERY, D.W., (2000), The National Morbidity, Mortality and Air Pollution Study, Part I: Methods and Methodological Issues, Research Report 94. Health Effects Institute, Cambridge, MA. (URL http: //www.healtheffects.org/Pub/Samet.pdf $2000 / 10 / 24)$

[8] SchwarTz, J., (2000), "Harvesting and long term exposure effects in the relation between air pollution and mortality", Am. J. Epidemiol., Vol. 151, pp. $440-448$.

[9] Šimić, D., Jazbec, A., Pavlović, M., ŠEGa, K., HRŠAK, J., (1998) "Short term effects of ambient $\mathrm{NO}_{2}$ on mortality in Zagreb", Proc. $20^{\text {th }}$ Int. Conf. Inf. Tech. Interfaces ITI'98, Pula, 16-19 Jun. 1998, ed. by D. Kalpić and V. Hljuz Dobrić, University Computing Centre, Zagreb, pp. 143-148.

[10] ŠImić, D., PaVlović, M., JaZBeC, A., Malinar, M., HRŠAK, J., ŠEGA, K., ŠoJAT, V., VAĐIĆ, V., (1999) "Short term effects of air pollution on general mortality in Zagreb, Croatia", Proc. $21^{\text {st }}$ Int. Conf. Inf. Tech. Interfaces ITI'99, Pula, 15-18 Jun. 1999, ed. by D. Kalpić and V. Hljuz Dobrić, University Computing Centre, Zagreb, pp. 169-175.

[11] Simonoff, J.S., AND TSAI, C.L., (1999), "Semiparametric and additive model selection using an improved Akaike information criterion", J. Comput. Graph. Stat., Vol. 8, pp. 22-40. 
[12] Zeger, S.L., Dominici, F., SAMET, J., (1999) "Harvesting-resistant estimates of air pollution effects on mortality", Epidemiol., Vol. 10, pp. 171175.

\author{
Received: June, 2001 \\ Accepted: September, 2001 \\ Contact address: \\ Diana Šimić, Mladen Pavlović, Krešimir Šega, \\ Janko Hršak and Vladimira Vađić \\ Institute for Medical Research and Occupational Health \\ Ksaverska cesta 2 \\ POB 291 \\ HR-10001 Zagreb \\ Croatia \\ e-mail: Diana.Simic@imi.hr \\ Mladen.Pavlovic@imi.hr, \\ Kresimir.Sega@imi.hr, \\ Vladimira.Vadic@imi.hr \\ Višnja Šojat \\ Meteorological and Hydrological Service, Republic of Croatia \\ Grič 3 \\ HR-10000 Zagreb \\ Croatia \\ e-mail: sojat@cirus.dhz.hr
}

DIANA ŠIMIĆ received her Ph.D. in 2001 from the University of Zagreb, Croatia. Currently she is a research assistant at the Institute for Medical Research and Occupational Health in Zagreb. She is working in the field of applied statistics and her main research interest is statistical modeling in environmental epidemiology.

MLAdEN PAVLović received his Ph.D. in 1986 from the University of Zagreb. Currently he is senior research associate at the Institute for Medical Research and Occupational Health in Zagreb. His main research interest is respiratory epidemiology.

KREŠIMIR ŠEGA received his Ph.D. in 1993 from the University of Zagreb, Croatia. Currently he is a senior research associate at the Institute for Medical Research and Occupational Health in Zagreb. He is working in the field of air pollution and his main research interests are particulate air pollution and exposure assessment to air pollutants.

JANKO HRŠAK received his $\mathrm{Ph} . \mathrm{D}$. in 1987 from the University of Zagreb, Croatia. Currently he is a senior research associate at the Institute for Medical Research and Occupational Health in Zagreb. He is working in the field of air pollution and his main research interest is the determination of heavy metal concentrations in the ambient air.

VLADIMIRA VAĐIĆ received her Ph.D. in 1984 from the University of Zagreb, Croatia. Currently she is a scientific advisor at the Institute for Medical Research and Occupational Health in Zagreb. She is working in the field of air pollution and her main research interests are general air pollution and monitoring networks.

VIŠNJA ŠOJAT received her M.Sc. in 1980 from the University of Zagreb. Currently she is the Head of the Chemical laboratory for air and water quality at the Meteorological and Hydrological Service, Republic of Croatia. Her main interests are acid rain monitoring and determination. 